\title{
Effect of high versus low doses of fat and vitamin A dietary supplementation on fatty acid composition of phospholipids in mice
}

\author{
Kathrin Weiss · Johanna Mihály • Gerhard Liebisch • \\ Tamás Marosvölgyi • Ada L. Garcia • \\ Gerd Schmitz • Tamás Decsi • Ralph Rühl
}

Received: 13 July 2013/Accepted: 11 November 2013/Published online: 4 December 2013

(C) Springer-Verlag Berlin Heidelberg 2013

\begin{abstract}
Dietary fat and vitamin A provide important precursors for potent bioactive ligands of nuclear hormone receptors, which regulate various enzymes involved in lipid homeostasis, metabolism and inflammation. We determined the effects of dietary fat and dietary vitamin A on hepatic expression of two fatty acid metabolizing enzymes, elongase 6 (ELOVL6) and stearoyl-coenzyme A desaturase 1 (SCD1) and the concentration of saturated fatty acids (SAFA) and monounsaturated fatty acid (MUFA) of phospholipids in serum and liver. Mice $(n=6)$ were fed 4 weeks with diets containing 2,5 and $25 \%$ of fat or vitamin A $(0,2,500$ and $326,500 \mathrm{RE} / \mathrm{kg}$ as retinyl palmitate). MUFAs and SAFAs were measured using GC and ESI-MS/MS. Hepatic expression of metabolizing enzymes was determined using QRT-PCR. ELOVL6 was significantly down-regulated in response to a high-fat diet $(p<0.001)$ and significantly up-regulated in response to low-fat diet $(p<0.05)$. SCD1 expression was significantly lower in high- versus low-fat diet $(p<0.05)$. The vitamin
\end{abstract}

K. Weiss · J. Mihály · R. Rühl $(\bowtie)$

Department of Biochemistry and Molecular Biology,

Medical and Health Science Center, University of Debrecen,

Nagyerdei Krt. 98, Debrecen 4032, Hungary

e-mail: ralphruehl@web.de

G. Liebisch · G. Schmitz

Institute of Clinical Chemistry and Laboratory Medicine,

University of Regensburg, Regensburg, Germany

T. Marosvölgyi · T. Decsi

Department of Paediatrics, University of Pécs, Pecs, Hungary

\section{A. L. Garcia}

Human Nutrition, School of Medicine, College of Medical, Veterinary and Life Sciences, University of Glasgow,

Glasgow, UK
A content in the diet did not influence the hepatic expression of both enzymes. In plasma, the amounts of MUFAs bound to phospholipids significantly decreased in response to a high-fat diet and increased after a low-fat diet. This tendency was also observed in the liver for various phospholipids sub-classes. In summary, this study shows that fat content in the diet has a stronger impact than the content of vitamin A on hepatic gene expression of SCD1 and ELOVL6 and thereby on MUFA and SAFA concentrations in liver and plasma.

Keywords Vitamin A · Poly-unsaturated fatty acids .

Desaturase $\cdot$ Elongase $\cdot$ Phospholipids

$\begin{array}{ll}\text { Abbreviations } \\ \text { SCD1 } & \text { Stearoyl-coenzyme A desaturase } 1 \\ \text { ELOVL6 } & \text { Elongase 6 } \\ \text { MUFA } & \text { Monounsaturated fatty acid } \\ \text { SAFA } & \text { Saturated fatty acid } \\ \text { RETPAL } & \text { Retinyl palmitate } \\ \text { RE } & \text { Retinol equivalence } \\ \text { RXR } & \text { Retinoid X receptor } \\ \text { RAR } & \text { Retinoic acid receptor } \\ \text { PC } & \text { Phosphatidylcholine } \\ \text { PE } & \text { Phosphatidylethanolamine } \\ \text { LPC } & \text { Lysophosphatidylcholine }\end{array}$

\section{Introduction}

Vitamin A is a fat-soluble vitamin, which is able to regulate gene expression via activation of nuclear hormone receptors (Mangelsdorf and Evans 1995). The vitamin A 
metabolites, all-trans retinoic acid (ATRA) and 9-cis retinoic acid (9CRA) act as a ligands to activate retinoid $\mathrm{X}$ receptor (RXR)- and retinoic acid receptor (Samuel et al.)mediated pathways (Mangelsdorf and Evans 1995). Additionally, other lipid-derived substances such as monohydroxylated fatty acids, leukotrienes and prostaglandins are active metabolites of the nuclear hormone receptors, in particular the RXR (Szanto et al. 2004) and the PPARs (Krey et al. 1997; Lampen et al. 2001). This phenomenon is relevant in the case of the RXR as it influences various metabolic pathways via hetero-dimerization with other nuclear hormone receptors (Cordain et al. 2005; Shulman and Mangelsdorf 2005), which in turn activate other pathways regulating the hepatic expression of the two fatty acid metabolizing enzymes SCD1 and ELOVL6 (Weiss et al. 2011). Lipid metabolism in the inflammation process, hormone signaling and energy homeostasis are major targets of the RXR- and RAR-mediated pathways (Cordain et al. 2005; Shulman and Mangelsdorf 2005).

SCD1 and ELOVL6 are crucial enzymes for the synthesis of specific monounsaturated fatty acids (Matsuzaka et al. 2007; Ntambi and Miyazaki 2004). SCD1 desaturates 16:0 and $18: 0$ to $16: 1 \mathrm{n}-7$ and $18: 1 \mathrm{n}-9$, respectively, while ELOVL6 elongates $16: 0,16: 1 \mathrm{n}-7$ and $18: 1 \mathrm{n}-9$ to $18: 0$, 18:1n-7 and 20:1n-9 (Matsuzaka et al. 2007; Wang et al. 2006; Ntambi and Miyazaki 2004), respectively. The hepatic expression of these enzymes has been shown to be induced via synthetic ligand activation of the RXR (Weiss et al. 2011; Singh Ahuja et al. 2001). We have shown that the regulation of hepatic SCD1 and ELOVL6 expression correlates closely with serum and hepatic contributions of MUFA and SAFA bound to phospholipids (Weiss et al. 2011). Phospholipids of mammals are constituents of intracellular and extracellular cell membranes and various lipoproteins (Quinn 1981). The most abundant phospholipids are phosphatidylethanolamine (PE) and phosphatidylcholine (PC), which contain each two bound fatty acids, mainly combinations of 16:0, 18:0 or 18:1 (McMurchie 1988; Flowers and Ntambi 2009). Besides, PE and PC also lysophosphatidylcholine (LPC) derived from PC are present in membrane structures (Quinn 1981).

Vitamin A derived from retinoic acid has been reported to induce the gene expression of SCD1 (Mauvoisin and Mounier 2011), while the induction of ELOVL6 gene expression was shown via RXR-activation by specific synthetic ligands (Weiss et al. 2011). Due to the key relation between MUFA and SAFA in phospholipids and the role of vitamin A and dietary fat on the activation of regulation gene expression of fatty acid metabolizing enzymes, it is important to elucidate which ingredient of diets plays the decisive role in the regulation of these enzymes. Therefore, the aim of this study was to investigate how the content of vitamin A and dietary fat in the diet may influence the hepatic expression of ELOVL6 and SCD1, and whether these alterations have an effect on serum and hepatic SAFA and MUFA concentrations.

\section{Materials and Methods}

Animal experiments were performed at the Laboratory Animal Core Facility of the University of Debrecen (Debrecen, Hungary) in accordance with the ethical guidelines of Hungary.

\section{Animal Study}

Six-to-eight-week-old female C57BL6 mice, purchased from Charles River (Budapest, Hungary), were fed for 2 weeks with regular chow (VRF1, Altromin GmbH, Lage,

Table 1 Diet and feeding scheme of different dietary combinations of fat (sunflower oil) and of vitamin A

\begin{tabular}{llllll}
\hline Ingredients (g/kg diet) & Diet groups & & & \\
\cline { 2 - 6 } & Low Fat (LF, 2 \%) & $\begin{array}{l}\text { Normal Fat (NF, 5 \%) } \\
\text { VA deficient }\end{array}$ & $\begin{array}{l}\text { Normal Fat (NF, 5 \%) } \\
\text { VA normal }\end{array}$ & $\begin{array}{l}\text { Normal Fat (NF, 5 \%) } \\
\text { VA high }\end{array}$ & $\begin{array}{l}\text { High Fat (HF, 25 \%) } \\
\text { VA normal }\end{array}$ \\
\hline Starch & 430 & 415 & 415 & 415 & 325 \\
Sucrose & 295 & 280 & 280 & 280 & 170 \\
Sunflower oil & 20 & 50 & 50 & 50 & 250 \\
Casein & 180 & 180 & 180 & 180 & 180 \\
Mineral mix & 45 & 45 & 45 & 45 & 10 \\
Vitamin Mix & 10 & 10 & 10 & 326,500 & 10 \\
Total VA content & 2,500 & 0 & 2,500 & & 2,500 \\
$\quad$ RE/kg diet) & & & &
\end{tabular}

\footnotetext{
${ }^{a}$ Vitamin mix in the normal-fat diet group provided different concentrations of vitamin A: vitamin mix without vitamin A (VA deficient diet), vitamin mix with vitamin A containing 2,500 RE/kg retinyl palmitate (RETPAL) (VA normal diet), vitamin mix with high vitamin A containing in total 326,500 RE/kg (VA high diet). Sunflower oil was added as dietary fat, which contained either $2 \%$ (low-fat diet), $5 \%$ (normal-fat diet) or $25 \%$ (high-fat diet)
} 
Germany). After the acclimatization period, the animals received for 10 weeks a vitamin A deficient (0 RE/kg diet) diet containing $5 \%$ sunflower oil as dietary lipid, which represented a diet with a normal fat content (Table 1, (Bonilla et al. 2000)). Animals were divided into different feeding groups ( $n=6$ per group) and were fed during 4 weeks with specific diets containing different amounts of dietary fat and equal amounts of vitamin A $(2,500 \mathrm{RE} / \mathrm{kg}$ diet, normal vitamin A). Additionally, the normal fat/normal vitamin A diet group was augmented by two other normal-fat diet groups receiving different amounts of vitamin $\mathrm{A}, 0 \mathrm{RE} / \mathrm{kg}$ diet (vitamin A deficient) and $326,500 \mathrm{RE} / \mathrm{kg}$ diet (vitamin A high) (Table 1). Mice had free access to water and food over the duration of the whole experiment. They were kept at $22{ }^{\circ} \mathrm{C}$ room temperature with a $12 \mathrm{~h}$ day/night cycle. All animals were killed by anesthesia with halothane. Blood collection was carried out by cardiac puncture. The blood was centrifuged for $10 \mathrm{~min}$, and plasma was stored at $-80{ }^{\circ} \mathrm{C}$. The mice were dissected, and liver samples were immediately frozen in liquid nitrogen and later stored at $-80{ }^{\circ} \mathrm{C}$.

\section{Diets}

Experimental diets were prepared with wheat starch (Weizenstärke FOODSTAR) provided by Kröner-Stärke (Ibbenbüren, Germany), sucrose (purchased from a local supermarket), casein from bovine milk purchased from Sigma-Aldrich (Budapest, Hungary), cellulose VIVAPUR provided by JRS Pharma GmbH \& Co. KG (Rosenberg, Germany), sunflower oil provided by Henry Lamotte (Bremen, Germany) and mineral mixture (Mineral-Spurenelemente-Vormischung C1000) purchased from Altro$\min \mathrm{GmbH}$ (Lage, Germany). Sunflower oil contained $67.9 \%$ of linoleic acid. For vitamin content, diets were added vitamin mix (Vitamin-Vormischung C1000) purchased from Altromin GmbH (Lage, Germany) containing either 2,500 RE (retinol equivalents) $/ \mathrm{kg}$ diet or no vitamin A (deficient diet). The final vitamin A concentration in normal diets was 2,500 and $326,500 \mathrm{RE} / \mathrm{kg}$ diet for high vitamin A diet. The high vitamin A concentration was achieved by adding 324,000 RE of retinyl palmitate supplement purchased from Sigma-Aldrich (Budapest, Hungary) per $\mathrm{kg}$ diet. The macronutrient content of the diets was not based on an isocaloric distribution, because the aim of the study was to provide high, normal and low fat content, and thus, the total amount of fat was equalized by increased or reduced amounts of carbohydrates (Table 1).

\section{RNA isolation from liver and QRT-PCR}

Total RNA was isolated from liver and quantified by QRTPCR (quantitative real-time PCR). Samples of liver tissue
(50 mg) were homogenized in Trizol (10 mg tissue/100 $\mu \mathrm{l}$ Trizol, Sigma-Aldrich, Budapest, Hungary) and extracted with chloroform (20/100 $\mu$ l Trizol). The aqueous phase was mixed with $700 \mu \mathrm{l}$ of ethanol (70 \% v/v) and loaded on the RNA isolation column (GenElute Mammalian Total RNA Miniprep Kit, Sigma-Aldrich, Budapest, Hungary). RNA was isolated from tissue according to the given protocol of Sigma-Aldrich and eluted in nuclease-free water. Concentration and purity were measured by Nanodrop (Thermo, Budapest, Hungary). cDNA was obtained by reverse transcription $\left(10 \min 25^{\circ} \mathrm{C}, 120 \min 42{ }^{\circ} \mathrm{C}\right.$, 5 min $72{ }^{\circ} \mathrm{C}$ ) and amplified via QRT-PCR (40 cycles: $12 \mathrm{~s}$ $94{ }^{\circ} \mathrm{C}, 45 \mathrm{~s} 60^{\circ} \mathrm{C}$, $\left.60 \mathrm{~s} 94^{\circ} \mathrm{C}\right)$. Primer and probe for expression analysis (Taq-Man-Gene Expression Assay) as well as quantitative real-time PCR detection system (ABIPRISM, 7900HT Sequence Detection System) were purchased from Applied Biosystems (Budapest, Hungary). The expression of genes was normalized to cyclophilin A (house-keeping gene): primer 77“+” 5'-CGATGACG AGCCCTTGG-3', primer 142“-” 5'-TCTGCTGTCTTT GGAACTTTGTC-3', probe $(69+, 96+)$ : FAM-CGCGT CTCCTTCGAGCTGTTTGCA, quencher tetramethylrhodamine (TAMRA). The amplification signal was detected and analyzed by the SDS2.1 program from Applied Biosystems, Budapest, Hungary.

Fatty acid analysis by gas chromatography (GC)

For the analysis of plasma fatty acids, frozen plasma samples were thawed and the pentadecanoylphosphatidylcholine (Phosphatidylcholine Dipentadecanoyl, Sigma-Aldrich, Budapest, Hungary) internal standard was added. Lipids were extracted by the addition of $3 \mathrm{ml}$ chloroform and $1 \mathrm{ml}$ methanol according to the method of Folch (Folch et al. 1957). The mixture was vortexed at 3,000 rpm for $15 \mathrm{~min}$. The lower layer was then aspirated into vials and evaporated under an N2 stream. Lipid extracts were reconstituted in $70 \mu \mathrm{l}$ chloroform, and lipid classes were separated by thin layer chromatography (TLC). The solvent mix for TLC of plasma lipids was as follows: hexane/diethyl ether/ chloroform/ acetic acid (21:6:3:1, v/v). The bands were stained with dichlorofluorescein, removed by scraping and transesterified in $1 \mathrm{ml}$ of $3 \mathrm{~N}-\mathrm{HCl}$-methanol solution (Methanolic $\mathrm{HCl}$, § N, Supelco, Budapest, Hungary) at $84{ }^{\circ} \mathrm{C}$ for $45 \mathrm{~min}$ (Decsi et al. 2007). Fatty acids were analyzed by high-resolution capillary GC using a Finnigan 9001 gas chromatograph (Finnigan/Tremetrics Inc., Austin, TX, USA) with split injection (ratio 1:25), automatic sampler (A200SE; CTC Analytic, Zwingen, $\mathrm{CH}$, USA) and flame ionization detector with a DB-23 cyanopropyl column of $40 \mathrm{~m}$ length (J\&W Scientific, Folsom, CA, USA). The temperature program was set to the following parameters: temperature 
of injector at $80{ }^{\circ} \mathrm{C} / \mathrm{min}$ up to $280{ }^{\circ} \mathrm{C}$, temperature of detector at $280{ }^{\circ} \mathrm{C}$, temperature of column area at $60{ }^{\circ} \mathrm{C}$ for $0.2 \mathrm{~min}$, temperature increase by $40^{\circ} \mathrm{C} / \mathrm{min}$ up to $180^{\circ} \mathrm{C}$, $5 \mathrm{~min}$ isothermal period, temperature increase by $1.5^{\circ} \mathrm{C} /$ min up to $200{ }^{\circ} \mathrm{C}, 8.5 \mathrm{~min}$ isothermal period, temperature increase by $40{ }^{\circ} \mathrm{C} / \mathrm{min}$ up to $240{ }^{\circ} \mathrm{C}$ and $13 \mathrm{~min}$ isothermal period. The constant linear velocity was $0.3 \mathrm{~m} / \mathrm{s}$ (referred to $100{ }^{\circ} \mathrm{C}$ ). Peak identification was confirmed by comparison with authentic mixtures of weighed fatty acid (FA) methyl esters (GLC-463: Nu-Chek Prep, Elysian, MN, USA; and Supelco 37 FAME Mix: Supelco, Bellefonte, PA, USA). Individual FA response factors determined from these weighed standards were used to calculate the percentage by weight for individual FA between 12 and 24 carbon atoms from the percentage of area under the curve.

Lipid species analysis in plasma and liver by ESI-MS/ MS

Liver homogenate and plasma were extracted according to the procedure described by Bligh and Dyer et al. (Bligh and Dyer 1959) in the presence of non-naturally occurring lipid species as internal standards. Lipids were quantified by electrospray ionization tandem mass spectrometry (ESIMS/MS) in positive ion mode as described previously by Brugger et al. (1997), Liebisch et al. (2006, 2004). Samples were quantified by direct flow injection analysis using the analytical protocol described by Liebisch et al. (2006, 2004). A precursor ion scan of $\mathrm{m} / z 184$ specific for phosphocholine containing lipids was used for phosphatidylcholine (PC), sphingomyelin (McClintick et al.) (Liebisch et al. 2004) and lysophosphatidylcholine (LPC) (Liebisch et al. 2006). Neutral loss scans of 141 and 185 were used for phosphatidylethanolamine (PE) and phosphatidylserine (PS), respectively (Liebisch et al. 2004). Ceramide was analyzed similarly to a previously described methodology (Liebisch et al. 1999) using $N$-heptadecanoyl sphingosine as the internal standard. Quantification was achieved by standard addition calibration to liver homogenates or plasma using a number of naturally occurring lipid species for each lipid class. The following non-naturally occurring lipid species were used as internal standards: PC 28:0, 44:0, LPC 13:0, 19:0 PE 28:0, 40:0, PS 28:0, 40:0. Quantification was performed by standard addition calibration to plasma and liver homogenates using several naturally occurring lipid species for each lipid class (PC 34:1, 36:2, 38:4, 40:0; SM d18:1/16:0, d18:1/18:1, d18:1/ 18:0; LPC 16:0, 18:1, 18:0; PE 34:1, 36:2, 38:4, 40:6 and PE 16:0/20:4; PS 34:1, 36:2, 38:4, 40:6). All standards were purchased from Avanti Polar Lipids (Alabaster, AL, USA). Isotopic overlap corrections of lipid species as well as data analysis by self-programmed Excel macros were performed for all lipid classes according to the principles described previously (Liebisch et al. 2004). Lipid species were annotated according to the recently published proposal for shorthand notation of lipid structures that are derived from mass spectrometry (Liebisch G, Vizcaíno JA, Köfeler H, Trötzmüller M, Griffiths WJ, Schmitz G, Spener F, Wakelam MJ. Shorthand notation for lipid structures derived from mass spectrometry. J Lipid Res. 2013 Jun; 54(6):1523-30.). Glycerophospholipid annotation is based on the assumption of even-numbered carbon chains only. The amounts of incorporated fatty acids were calculated as percentages. The normal fat, normal vitamin A diet (NF VA norm) was set as a referent (100\%), and the other diets were calculated as a difference from normal fat, normal vitamin A diet.

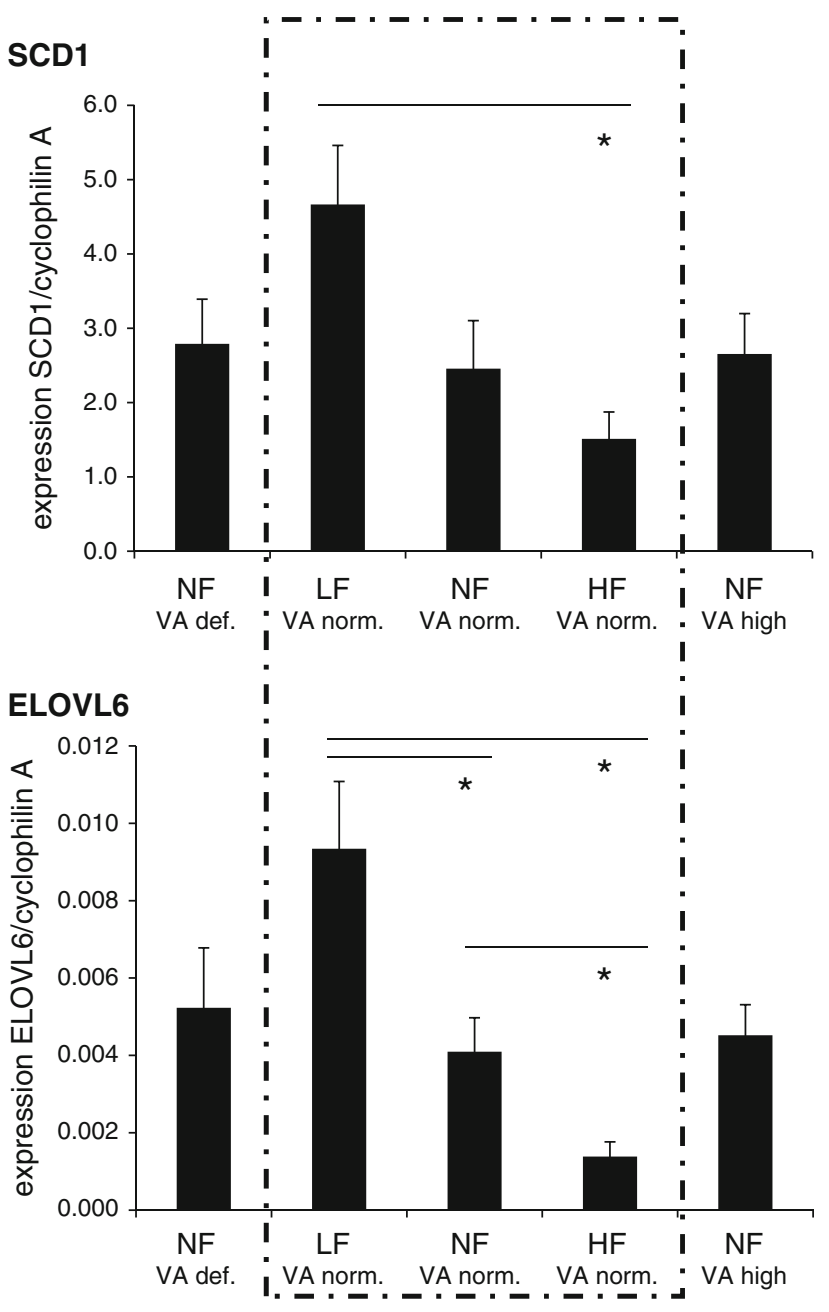

Fig. 1 Hepatic expression of SCD1 and ELOVL6 determined by QRT-PCR after diets low and high in dietary fat or higher in vitamin A. $L F$ low-fat diet, $N F$ normal-fat diet, $H F$ high-fat diet, $V A$ vitamin A, def. deficient, norm. normal. Statistical analysis was displayed as $* p<0.05 ; * * p<0.001$ 
Statistical analysis

Results are shown as mean and standard error. The effect of diet was analyzed using ANOVA followed by Bonferroni post hoc test. All statistical analysis were done using SPSS (15.0) software (SPSS Inc., Chicago, USA). Statistically significance was accepted at $p<0.05$.

\section{Results}

Influence of dietary fat on lipid composition and hepatic enzyme expression

\section{Hepatic expression of SCD1 and ELOVL6}

The highest hepatic gene expression of SCD1 and ELOVL6 was observed in mice fed a low-fat (LF) compared to mice fed a high-fat (HF) diet (Fig. 1). The hepatic gene expression of ELOVL6 was significantly higher in mice fed LF diet compared to the other diets. The alteration of gene expression of these two enzymes in liver displayed a tendency to decrease with an increasing amount of dietary fat.
Lipid composition in plasma by GC

The fatty acid composition in plasma phospholipids of animals fed diets with different amounts of fat was analyzed by GC to determine various SAFAs and MUFAs (Table 2). Dietary fat did not affect the total contribution of SAFAs. However, the content of the fatty acid 16:0 (palmitic acid) bound in phospholipids decreased after a $\mathrm{HF}$ diet compared to a LF diet. In contrast, mice fed a HF diet showed higher plasma values of the fatty acid 18:0 (stearic acid) bound in phospholipids compared to NF and LF diet.

The contribution of total MUFAs bound to phospholipids was higher in the LF diet versus the HF diet. The contributions of $18: 1 n-9$ and $18: 1 n-7$ were the highest in the LF diet. Significant lower values of the sum of all MUFAs as well as of 18:1n-9, 18:1n-7 and 20:1n-9 incorporated into phospholipids were observed in plasma of mice fed NF diet compared to the HF diet. Mice fed a LF diet showed significantly lower concentrations of 16:1n-7, 18:1n-9 and 18:1n-7 than those of mice fed a HF diet. Ratios of selected SAFAs and MUFAs are shown in Table 2. The ratio of total SAFAs divided by total MUFAs as well as the ratios of 18:0/16:0, 18:1n-7/16:1n-7 and 20:1n-9/18:1n-9 significantly increased after a HF diet

Table 2 Analysis of fatty acid composition by GC of plasma phospholipids in mice fed a diet containing different amounts of fat (sunflower oil) and vitamin A (VA)

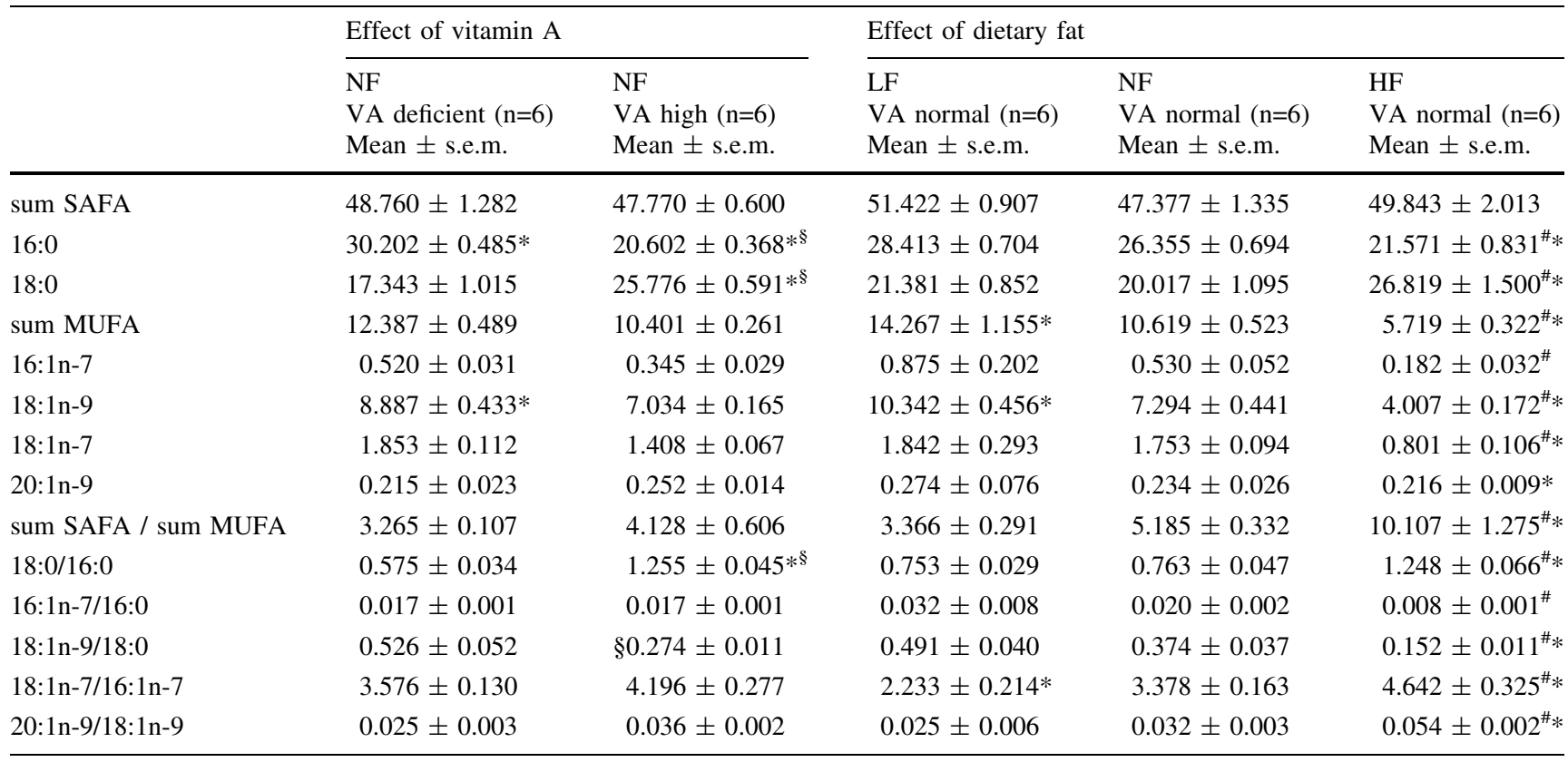

Amounts are displayed in mean in weight $\%$

s.e.m. standard error of mean, $S A F A$ saturated fatty acid, $M U F A$ monounsaturated fatty acid, $L F$ low fat, $N F$ normal fat, $H F$ high fat. Statistical analysis compared to control

$* p<0.05$ different to NF VA normal

\# $p<0.05$ different HF VA normal versus LF VA normal

$\S p<0.05$ different of NF VA deficient to NF VA high 


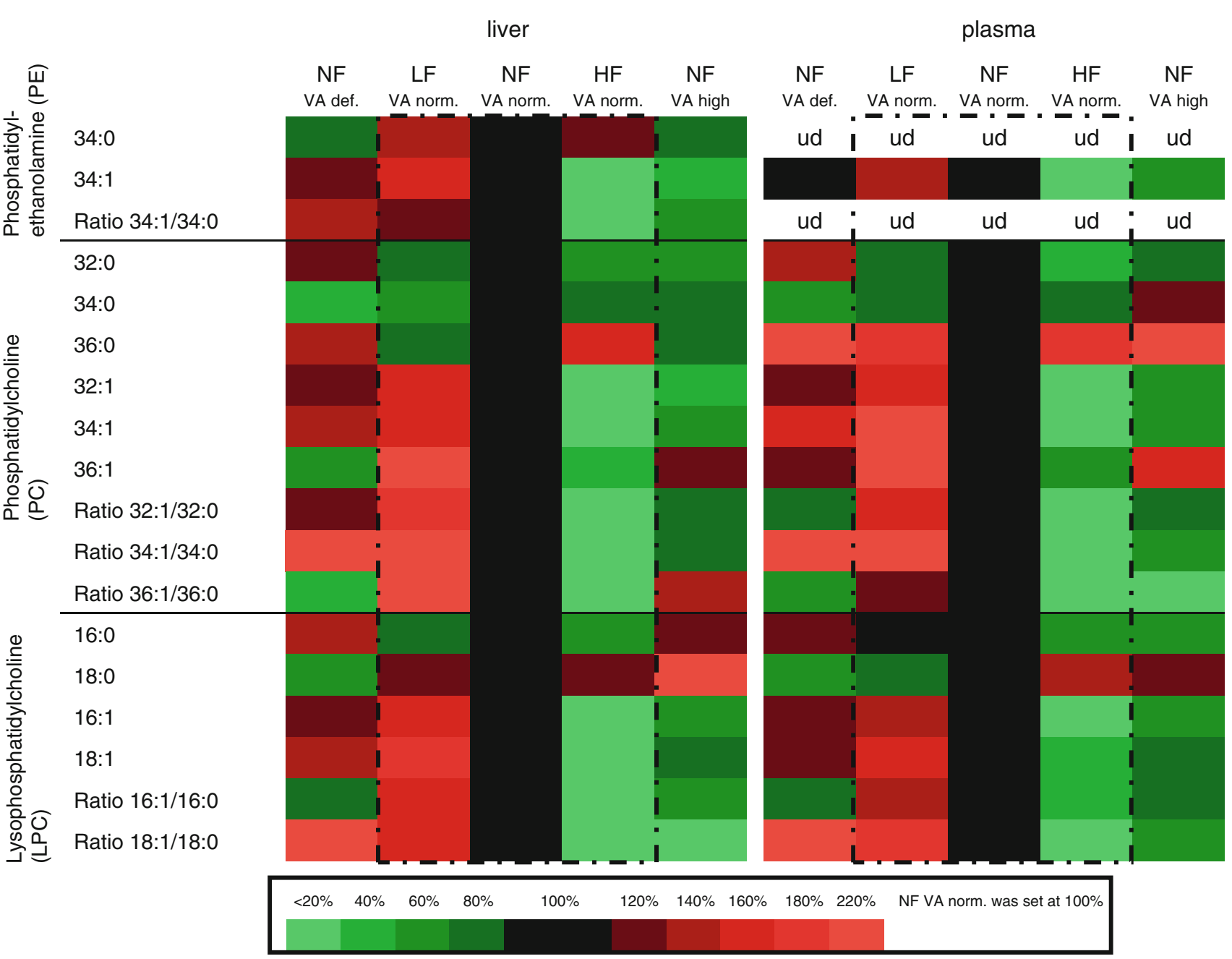

Fig. 2 Analysis of composition of PC, LPC and PE determined by ESI-MS/MS in liver and plasma after diets low and high in dietary fat or higher in vitamin A. $L F$ low-fat diet, $N F$ normal-fat diet, $H F$ highfat diet, VA vitamin A, def. deficient, norm. normal. The amount of each incorporated fatty acid was calculated in percent compared to

compared to a LF diet. The ratios of $16: 1 \mathrm{n}-7 / 16: 0$ and 18:1n-9/18:0 significantly decreased in the HF diet compared to the LF diet. Comparisons between ratios of NF diet to HF diet showed a decrease in 18:0/16:0, 18:1n-7/ $16: 1 \mathrm{n}-7$ and 20:1n-9/18:1n-9, while 18:1n-9/18:0 increased. The ratio of $18: 1 n-7 / 16: 1 n-7$ significantly decreased comparing LF diet with HF diet.

ESI-MS/MS analysis of fatty acids bound to several types of phospholipids in plasma and liver

The fatty acid composition of the selected phospholipids PE, PC and LPC was analyzed in liver and plasma by ESIMS/MS, and their presence is shown in Fig. 2. PC and PE contained each two bound fatty acids, while in LPC only one fatty acid was bound. Red labeled displayed an increase in fatty acids, while green labeled displayed a the NF-VA norm. feeding group, which represents $100 \%$ (black). Red colors display an increased amount of this particular fatty acid, while green means a decrease compared to the NF-VA norm. feeding group (color figure online)

decrease. Red and green results are compared against normal fat/normal vitamin A diet, which is depicted in black and is used as the $100 \%$ referent.

In liver phospholipids, mice fed LF diets showed increased incorporation of PE 34:1, PC 32:1, 34:1, 36:1 and LPC 16:1, 18:1, 18:0 compared to NF diet. Lower percentages of incorporated fatty acids were observed in PC 32:0, 36:0 and LPC 16:0. Furthermore, ratios of PE 34:1/ 34:0, PC 32:1/32:0, 34:1/34:0, 36:1/36:0 and LPC 16:1/ 16:0, 18:1/18:0 also decreased. HF diet compared to NF diet displayed a decrease in PE 34:1, PC 32:1, 34:1, 36:1 and LPC 16:1, 18:1, 16:0. An increase was measured in PE 34:0 and PC 36:0.

In plasma phospholipids, mice fed LF diet had higher incorporation of PE 34:1, PC 32:1, 34:1, 36:0, 36:1 and LPC 16:1, 18:1 compared to NF diet, and the ratios of PC 32:1/32:0, 34:1/34:0, 36:1/36:0 and LPC 16:1/16:0, 18:1/ 
18:0 decreased. An increase was measured for PC 32:0, 34:0, 36:0 and LPC 18:0. Comparing HF diet with NF diet concentrations of PE 34:1, PC 32:1, 34:1, 36:1 and LPC 16:0, 16:1, 18:1 decreased. Ratios of PC 32:1/32:0, 34:1/ 34:0, 36:1/36:0 and LPC 16:1/16:0, 18:1/18:0 increased as well.

In summary, LF diets resulted in more MUFAs than SAFAs being incorporated in phospholipids in both liver and plasma. In contrast, mice fed HF diets showed more SAFAs and less MUFAs being incorporated to phospholipids.

Influence of different amounts of dietary vitamin A

\section{Hepatic expression of SCD1 and ELOVL6}

NF diets were supplemented with different concentrations of vitamin A to determine vitamin A effect on gene expression and fatty acid composition. Different concentrations of dietary vitamin A had no effect on the hepatic expression of SCD1 and ELOVL6 (Fig. 1).

\section{Analysis of lipid composition in plasma and liver}

The total concentration of plasma SAFAs was not influenced by different amounts of vitamin A. However, when looking at individual SAFA's and specific phospholipids (Fig. 2), there was a significant increase in plasma concentrations of LPC 18:0 in mice fed high VA diet compared to VA deficient diet. In contrast, plasma concentrations of LPC 16:0 were higher in animals receiving a deficient vitamin A diet compared to animals receiving a high vitamin A diet. This result was also observed in plasma phospholipids analyzed by GC incorporating lower amounts of 16:0 and higher amounts of 18:0 after a high vitamin A diet.

The analysis via GC revealed that the total amount of MUFA was not influenced by dietary vitamin A. However, the ratio of 18:1n-9/18:0 decreased significantly in mice fed VA deficient diet compared to those fed the high vitamin A diet. Other ratios were not influenced by dietary vitamin A.

The analysis of PE, PC and LPC species in liver and plasma showed an increase in LPC 18:1 and LPC 16:1 concentrations in liver and plasma of mice fed VA deficient diets compared to high vitamin A diet (Fig. 2). This increase was also been observed in liver and plasma for PC 32:1 and 34:1 as well as for PE 34:1.

\section{Discussion}

The influence of diet on gene expression is of great interest from the point of view of understanding how dietary changes may affect physiological pathways linked to important cell functions. Vitamin A and dietary fat are strong regulators of specific target genes, which in turn are essential to several cell functions. This study was conducted to investigate to which extend dietary fat or vitamin A can influence the hepatic gene expression of the same set target genes and influence serum and hepatic fat content. High amount of dietary fat rich in n6-PUFAs suppressed, while low amount increased the hepatic expression of the investigated target genes, SCD1 and ELOVL6. In addition, the metabolic products (MUFAs) and ratios (SAFA/ MUFA) of these two enzymes were altered in serum and liver. Surprisingly, the vitamin A content did not strongly influence either the enzyme expression or the corresponding serum and liver MUFA/SAFA ratios and product values.

Linoleic acid (18:2n-6), the main fatty acid in sunflower oil, belongs to the group of PUFAs known to inhibit the expression of specific genes via the SREBP, a transcription factor for genes specific to fat metabolism and inducer of the transcription of SCD1 and ELOVL6 enzymes (Jump et al. 2005). Nutrients such as carbohydrates, saturated fatty acids or cholesterol have shown to induce the SREBP (Repa et al. 2000; Miyazaki et al. 2004; Mauvoisin and Mounier 2011) via specific nuclear hormone receptor pathways (Repa et al. 2000), resulting in an increased SCD1 expression (Repa et al. 2000).

It has been well established since 1,978 that linoleic acid contained in sunflower oil decreased hepatic gene expression of SCD1 in a dose-dependent manner (Jeffcoat and James 1978). We investigated further the effect of linoleic acid from sunflower oil on the composition of hepatic and plasmatic phospholipids containing the substrates and metabolic products of this enzyme to gain further insight into the role of linoleic acid on fatty acid metabolizing enzymes. We used sunflower oil as the regulating fat in the diets due to the well-described regulatory characteristics on our target genes (Jeffcoat and James 1978) and well tolerability by the laboratory animals, which was discovered by previous experiments. Our results showed that high hepatic expression of SCD1 was accompanied by high amounts of the metabolic product 18:1n-9, while the amount of 18:0 SCD1 substrates was low. Conversely, a low hepatic SCD1 expression was observed together with low amounts of the metabolic products incorporated into phospholipids in liver and plasma. We also investigated the effects of linoleic acid on ELOVL6 expression in liver and plasma and observed similar results to the ones of SCD1. Our observations are in line with Wang et al. who suggested that the expression of ELOVL6 is regulated via the SREBP pathway in a similar fashion to SCD1 (Wang et al. 2006).

Furthermore, in this study, it was shown that also the amounts of the enzyme substrates as well as the metabolic 
products incorporated in phospholipids are affected by this specific dietary fat. The ratios of metabolic products to substrates (18:0/16:0, 18:1n-7/16:1n-7, 20:1n-9/18:1n-9) decreased after high-fat diet, which could be a result of the reduced enzymatic activity of ELOVL6. In previous studies, using synthetic ligands to induce the hepatic expression of ELOVL6 by specific transcription factors (nuclear hormone receptors), an increase in metabolic products incorporated in phospholipids has been reported (Weiss et al. 2011; Matsuzaka et al. 2007).

The meaning of the observed alteration in the composition of phospholipids in membranes is difficult to evaluate because there are only few studies that have investigated the effect of nutrients on the physicochemical characteristics or on the impact on function of membranes. The inhibition of SCD1 and ELOVL6 leads to a reduction in MUFAs incorporated into membranes and to an increase in SAFA's in membrane phospholipids. Increased amounts of SAFA's incorporated in phospholipids might cause a more rigid structure of cell membranes (Schachter 1984; Hodson et al. 2008). Alteration of the membrane structure affects not only the physical properties, such as membrane fluidity and agglutination (Spector and Yorek 1985), but also cellular function. Cellular transport across the membrane (e.g., transport of short-chain, neutral amino acids) as well as receptor signaling (e.g., insulin) is influenced by the saturation status of the membrane (Spector and Yorek 1985). Additionally, membranes composed of high amounts of PUFAs are more sensitive to oxidative stress, which effect can lead to cellular damage and consequent reduction in the general health and lifespan of body cells (Hulbert 2010).

Metabolites of vitamin A are known to induce expression of enzymes involved in fat metabolism. Genes of SCD1 and ELOVL6 are targets of RXR in liver (Weiss et al. 2011; Samuel et al. 2001; Singh Ahuja et al. 2001), which is activated by the natural ligands derived from dietary vitamin A (Samuel et al. 2001; McClintick et al. 2006) and by synthetic ligands (Weiss et al. 2011; Samuel et al. 2001). It has also been suggested that vitamin A induces the hepatic gene expression of SCD1 (Mauvoisin and Mounier 2011). However, we have previously shown that the induction of SCD1 via dietary vitamin A-dependent pathways is not straightforward (Weiss et al. 2011). RXR induces the expression, while RAR tends to suppress the expression of SCD1 in liver, which leads to an alteration of the phospholipid composition in plasma and liver (Weiss et al. 2011).

On the one hand, the hepatic expression of SCD1 can be induced via the RXR-dependent pathway as shown via activation using natural dietary vitamin A ligands (Samuel et al. 2001) and synthetic ligands for RXR (Weiss et al. 2011). Both receptors are induced by different forms of vitamin A (9-cis retinoic acid and all-trans retinoic acid). On the other hand, ELOVL6 is induced via the RXR pathway, but not via the RAR receptor pathway (Weiss et al. 2011). In the present study, different amounts of dietary vitamin A were supplied in combination with dietary fat rich in linoleic acid. Neither the hepatic expression of ELOVL6 nor of SCD1 was affected by high or deficient levels of VA. This surprising result might be explained by the different impact of n6-fatty acids and vitamin A on gene expression. N6-fatty acids are part of the PUFA family, which are known to suppress the expression of SCD1 in liver (Jeffcoat and James 1978; Jump et al. 2005), while vitamin A is suggested to induce it (McClintick et al. 2006). Our results suggest that dietary fat has a stronger impact on the gene expression of SCD1 than vitamin A.

Even though VA supplementation had no effect on the hepatic expression of fatty acid metabolizing enzymes, an alteration in fatty acid composition in plasma was observed. High VA diet resulted in decreased concentrations of SAFA 16:0 and increased SAFA 18:0. An explanation might be the existence of a different fatty acid metabolizing enzyme, which converts $16: 0$ to $18: 0$ and is regulated by dietary vitamin A (McClintick et al. 2006). Another possibility could be the suppression of the de novo synthesis of fatty acids via suppressing the expression of acetyl-CoA-carboxylase (Vega et al. 2009; Oliveros et al. 2007), which in turn leads to a reduction in the main product 16:0 and therefore to an relative increase of 18:0.

\section{Conclusion}

Dietary fat was the main factor affecting the hepatic expression of SCD1 and ELOVL6 in mice with concomitant alterations of their metabolic products such as serum and hepatic MUFAs and SAFA/MUFA ratios. Both enzymes were modulated by dietary fat with high expression after low fat and low expression after high-fat diets. VA supplementation had no effect on hepatic enzyme expression nor serum and hepatic SAFA and MUFA concentrations.

Acknowledgments This study was conducted with support of Dr. Tamas Röszer and Eva Papp. The work/publication is supported by the TÁMOP 4.2.2.A-11/1/KONV-2012-0023 “VÉD-ELEM" project. The project is implemented through the New Hungary Development Plan co-financed by the European Social Fund and the European Regional Development Fund.

Ethical standards Kathrin Weiss, Johanna Mihály, Gerhard Liebisch, Tamás Marosvölgyi, Ada L. Garcia, Gerd Schmitz, Tamás Decsi and Ralph Rühl declare that they have no conflict of interest. All institutional and national guidelines for the care and use of laboratory animals were followed. 


\section{References}

Bligh EG, Dyer WJ (1959) A rapid method of total lipid extraction and purification. Can J Biochem Physiol 37(8):911-917

Bonilla S, Redonnet A, Noel-Suberville C, Pallet V, Garcin H, Higueret $P$ (2000) High-fat diets affect the expression of nuclear retinoic acid receptor in rat liver. Br J Nutr 83(6):665-671

Brugger B, Erben G, Sandhoff R, Wieland FT, Lehmann WD (1997) Quantitative analysis of biological membrane lipids at the low picomole level by nano-electrospray ionization tandem mass spectrometry. Proc Natl Acad Sci USA 94(6):2339-2344

Cordain L, Eaton SB, Sebastian A, Mann N, Lindeberg S, Watkins BA, O'Keefe JH, Brand-Miller J (2005) Origins and evolution of the Western diet: health implications for the 21st century. Am J Clin Nutr 81(2):341-354

Decsi TSE, Burus I, Marosvölgyi T, Kozári A, Erhardt E, Soltész G (2007) Low contribution of n-3 polyunsaturated fatty acids to plasma and erythrocyte membrane lipids in diabetic young adults. Prostaglandins Leukot Essent Fatty Acids 76:159-164

Flowers MT, Ntambi JM (2009) Stearoyl-CoA desaturase and its relation to high-carbohydrate diets and obesity. Biochim Biophys Acta 1791(2):85-91. doi:10.1016/j.bbalip.2008.12.011

Folch J, Lees M, Sloane Stanley GH (1957) A simple method for the isolation and purification of total lipides from animal tissues. J Biol Chem 226(1):497-509

Hodson L, Skeaff CM, Fielding BA (2008) Fatty acid composition of adipose tissue and blood in humans and its use as a biomarker of dietary intake. Prog Lipid Res 47(5):348-380. doi:10.1016/j. plipres.2008.03.003

Hulbert AJ (2010) Metabolism and longevity: is there a role for membrane fatty acids? Integr Comp Biol 50(5):808-817. doi:10. 1093/icb/icq007

Jeffcoat R, James AT (1978) The control of stearoyl-CoA desaturase by dietary linoleic acid. FEBS Lett 85(1):114-118

Jump DB, Botolin D, Wang Y, Xu J, Christian B, Demeure O (2005) Fatty acid regulation of hepatic gene transcription. J Nutr 135(11):2503-2506

Krey G, Braissant O, L'Horset F, Kalkhoven E, Perroud M, Parker MG, Wahli W (1997) Fatty acids, eicosanoids, and hypolipidemic agents identified as ligands of peroxisome proliferatoractivated receptors by coactivator-dependent receptor ligand assay. Mol Endocrinol 11(6):779-791

Lampen A, Meyer S, Nau H (2001) Phytanic acid and docosahexaenoic acid increase the metabolism of all-trans-retinoic acid and CYP26 gene expression in intestinal cells. Biochim Biophys Acta 1521(1-3):97-106

Liebisch G, Drobnik W, Reil M, Trumbach B, Arnecke R, Olgemoller B, Roscher A, Schmitz G (1999) Quantitative measurement of different ceramide species from crude cellular extracts by electrospray ionization tandem mass spectrometry (ESI-MS/ MS). J Lipid Res 40(8):1539-1546

Liebisch G, Lieser B, Rathenberg J, Drobnik W, Schmitz G (2004) High-throughput quantification of phosphatidylcholine and sphingomyelin by electrospray ionization tandem mass spectrometry coupled with isotope correction algorithm. Biochim Biophys Acta 1686(1-2):108-117

Liebisch G, Binder M, Schifferer R, Langmann T, Schulz B, Schmitz G (2006) High throughput quantification of cholesterol and cholesteryl ester by electrospray ionization tandem mass spectrometry (ESI-MS/MS). Biochim Biophys Acta 1761(1):121-128

Mangelsdorf DJ, Evans RM (1995) The RXR heterodimers and orphan receptors. Cell 83(6):841-850

Matsuzaka T, Shimano H, Yahagi N, Kato T, Atsumi A, Yamamoto $\mathrm{T}$, Inoue $\mathrm{N}$, Ishikawa $\mathrm{M}$, Okada $\mathrm{S}$, Ishigaki $\mathrm{N}$, Iwasaki $\mathrm{H}$, Iwasaki Y, Karasawa T, Kumadaki S, Matsui T, Sekiya M,
Ohashi K, Hasty AH, Nakagawa Y, Takahashi A, Suzuki H, Yatoh S, Sone H, Toyoshima H, Osuga J, Yamada N (2007) Crucial role of a long-chain fatty acid elongase, Elovl6, in obesity-induced insulin resistance. Nat Med 13(10):1193-1202

Mauvoisin D, Mounier C (2011) Hormonal and nutritional regulation of SCD1 gene expression. Biochimie 93(1):78-86. doi:10.1016/ j.biochi.2010.08.001

McClintick JN, Crabb DW, Tian H, Pinaire J, Smith JR, Jerome RE, Edenberg HJ (2006) Global effects of vitamin A deficiency on gene expression in rat liver: evidence for hypoandrogenism. J Nutr Biochem 17(5):345-355. doi:10.1016/j.jnutbio.2005.08.006

McMurchie EJ (1988) Dietary lipids and the regulation of membrane fluidity and function. In: Aloia RC (ed) Physiological regulation of membrane fluidity. Alan R Liss Inc., New York, pp 189-327

Miyazaki M, Dobrzyn A, Man WC, Chu K, Sampath H, Kim HJ, Ntambi JM (2004) Stearoyl-CoA desaturase 1 gene expression is necessary for fructose-mediated induction of lipogenic gene expression by sterol regulatory element-binding protein-1cdependent and -independent mechanisms. J Biol Chem 279(24):25164-25171. doi:10.1074/jbc.M402781200

Ntambi JM, Miyazaki M (2004) Regulation of stearoyl-CoA desaturates and role in metabolism. Prog Lipid Res 43(2):91-104

Oliveros LB, Domeniconi MA, Vega VA, Gatica LV, Brigada AM, Gimenez MS (2007) Vitamin A deficiency modifies lipid metabolism in rat liver. Br J Nutr 97(2):263-272. doi:10.1017/ S0007114507182659

Quinn PJ (1981) The fluidity of cell membranes and its regulation. Prog Biophys Mol Biol 38(1):1-104

Repa JJ, Liang G, Ou J, Bashmakov Y, Lobaccaro JM, Shimomura I, Shan B, Brown MS, Goldstein JL, Mangelsdorf DJ (2000) Regulation of mouse sterol regulatory element-binding protein1c gene (SREBP-1c) by oxysterol receptors. LXRalpha and LXRbeta. Genes Dev 14(22):2819-2830

Samuel W, Kutty RK, Nagineni S, Gordon JS, Prouty SM, Chandraratna RA, Wiggert B (2001) Regulation of stearoyl coenzyme A desaturase expression in human retinal pigment epithelial cells by retinoic acid. J Biol Chem 276(31):28744-28750

Schachter D (1984) Fluidity and function of hepatocyte plasma membranes. Hepatology 4(1):140-151

Shulman AI, Mangelsdorf DJ (2005) Retinoid X receptor heterodimers in the metabolic syndrome. The New England J Med 353(6):604-615

Singh Ahuja H, Liu S, Crombie DL, Boehm M, Leibowitz MD, Heyman RA, Depre C, Nagy L, Tontonoz P, Davies PJ (2001) Differential effects of rexinoids and thiazolidinediones on metabolic gene expression in diabetic rodents. Mol Pharmacol 59(4):765-773

Spector AA, Yorek MA (1985) Membrane lipid composition and cellular function. J Lipid Res 26(9):1015-1035

Szanto A, Narkar V, Shen Q, Uray IP, Davies PJ, Nagy L (2004) Retinoid X receptors: X-ploring their (patho) physiological functions. Cell Death Differ 11(Suppl 2):S126-S143

Vega VA, Anzulovich AC, Varas SM, Bonomi MR, Gimenez MS, Oliveros LB (2009) Effect of nutritional vitamin A deficiency on lipid metabolism in the rat heart: its relation to PPAR gene expression. Nutrition 25(7-8):828-838. doi:10.1016/j.nut.2009.01.008

Wang Y, Botolin D, Xu J, Christian B, Mitchell E, Jayaprakasam B, Nair MG, Peters JM, Busik JV, Olson LK, Jump DB (2006) Regulation of hepatic fatty acid elongase and desaturase expression in diabetes and obesity. J Lipid Res 47(9):2028-2041

Weiss K, Mihaly J, Liebisch G, Marosvolgyi T, Schmitz G, Decsi T, Ruhl R (2011) Effect of synthetic ligands of PPAR alpha, beta/ delta, gamma, RAR, RXR and LXR on the fatty acid composition of phospholipids in mice. Lipids 46(11):1013-1020. doi:10.1007/s11745-011-3593-6 